\title{
Cerebrospinal fluid and serum IL-8, CCL2, and ICAM-1 concentrations in astrocytic brain tumor patients
}

\author{
O. M. Koper ${ }^{1}$ - J. Kamińska ${ }^{1} \cdot$ K. Sawicki ${ }^{2} \cdot$ J. Reszeć $^{3} \cdot$ R. Rutkowski ${ }^{2} \cdot$ M. Jadeszko $^{2}$. \\ Z. Mariak $^{2}$ - V. Dymicka-Piekarska ${ }^{1} \cdot$ H. Kemona ${ }^{1}$
}

Received: 21 June 2017 / Accepted: 4 October 2017 /Published online: 30 October 2017

(C) The Author(s) 2017. This article is an open access publication
Abstract
Background The aim of the study was the evaluation of serum and CSF concentrations of CCL2, IL-8, and sICAM-1 in patients with astrocytic tumors as compared to a group of non-tumoral patients.
Methods Chemokine concentrations were measured using the ELISA method.
Results Regardless of the parameter tested and the patient group (brain tumor or non-tumoral patients), statistical differ- ences $(P<0.05)$ were found between concentrations obtained in CSF compared to values obtained in serum for all proteins tested. CSF IL-8 concentrations were significantly elevated in CNS tumor patients as compared to non-tumoral individuals $(P=0.000)$; serum CCL2 and sICAM-1 concentrations were significantly decreased in CNS tumors in comparison with the comparative group ( $P=0.002$ and $P=0.026$, respectively). Among proteins tested in the serum, a higher area under the ROC curve (AUC) revealed CCL2 compared to sICAM-1 in differentiating subjects with CNS brain tumors from non- tumoral subjects. AUC for CSF IL-8 was higher than for its index (CSF IL-8/serum IL-8).
Conclusions For individual biomarkers (IL-8 and CCL2, sICAM-1), measured in CNS brain tumor patients, the
O. M. Koper
o.koper@wp.pl
appropriate material, respectively CSF or serum, should be chosen and quantitatively tested. Increased cerebrospinal fluid IL-8 with decreased serum CCL2 create a pattern of bio- markers, which may be helpful in the management of CNS astrocytic brain tumors.
Keywords Biomarkers · CCL-2 - CNS brain tumors · IL-8 . sICAM-1

$\begin{array}{ll}\text { Abbreviations } & \\ \text { AUC } & \text { Area under the ROC curve } \\ \text { BBB } & \text { Blood brain barrier } \\ \beta N G F & \text { Nerve growth factor beta } \\ \text { cDNA } & \text { Complementary deoxyribonucleic acid } \\ \text { CNS } & \text { Central nervous system } \\ \text { CSCs } & \text { Cancer stem cells } \\ \text { CSF } & \text { Cerebrospinal fluid } \\ \text { CXCL4 } & \text { CXC chemokine ligand 4 } \\ \text { CXCR1 } & \text { C-X-C motif chemokine receptor 1 } \\ \text { CXCR2 } & \text { C-X-C motif chemokine receptor 2 } \\ \text { EAE } & \text { Experimental autoimmune } \\ & \text { encephalomyelitis } \\ \text { ECs } & \text { Endothelial cells } \\ \text { EGFR } & \text { Epidermal growth factor receptor } \\ \text { ELISA } & \text { Enzyme-linked immunosorbent } \\ & \text { assay } \\ \text { ELR } & \text { Chemokine with a specific amino } \\ & \text { acid sequence (or motif) of } \\ \text { FGF } & \text { glutamic acid-leucine-arginine } \\ \text { GBM } & \text { Fibroblast growth factor } \\ \text { GFAP } & \text { Glioblastoma } \\ \text { GM-CSF } & \text { Glial fibrillary acidic protein } \\ & \text { Granulocyte macrophage } \\ \text { colony-stimulating factor }\end{array}$
Department of Clinical Laboratory Diagnostics, Medical University of Bialystok, ul. Waszyngtona 15A, 15-269 Białystok, Poland
FGF
Department of Neurosurgery, Clinical Hospital of the Medical University of Bialystok, Białystok, Poland
3 Department of Pathomorphology, Medical University of Bialystok, Białystok, Poland 


$\begin{array}{ll}\text { ICAM-1/CD54 } & \text { Intercellular adhesion molecule-1 } \\ \text { IDH1 } & \text { Isocitrate dehydrogenase 1 } \\ \text { IFN- } \gamma & \text { Interferon gamma } \\ \text { IL } & \text { Interleukin } \\ \text { IL1R } \alpha & \text { Interleukin 1 receptor } \\ \text { Ki-67 } & \text { Ki-67 protein } \\ \text { LIF } & \text { Leukemia inhibitory factor } \\ \text { LPS } & \text { Lipopolysaccharides } \\ \text { MCP-1/CCL2 } & \text { Monocyte chemotactic protein-1 } \\ \text { MIA } & \text { Multiplex immuno-assay } \\ \text { MIP1 } \alpha & \text { Macrophage inflammatory } \\ & \text { protein 1 alpha } \\ \text { mRNA } & \text { Messenger ribonucleic acid } \\ \text { NFKB1 } & \text { Nuclear factor kappa B subunit 1 } \\ \text { NK cell } & \text { Natural killer cell } \\ \text { p53 } & \text { Tumor protein p53 } \\ \text { PTEN } & \text { Phosphatase and tensin homolog } \\ \text { ROC } & \text { Receiver operator characteristic } \\ \text { S100A8 } & \text { S100 calcium-binding protein A8 } \\ \text { S100A9 } & \text { S100 calcium-binding protein A9 } \\ \text { SCGF } \beta & \text { Stem cell growth factor beta } \\ \text { SELDI-ToF MS } & \text { Surface-enhanced laser } \\ & \text { desorption/ionization-time } \\ & \text { of flight-mass } \\ \text { TAMs } & \text { Tumor associated macrophages } \\ \text { TNF- } \alpha & \text { Tumor necrosis factor } \alpha \\ \text { UIA } & \text { Unruptured brain aneurysm } \\ \text { VACAM-1 } & \text { Vascular cell adhesion molecule-1 } \\ \text { VEGF } & \text { Vascular endothelial growth factor } \\ \text { WHO } & \text { World Health Organization } \\ & \\ & \end{array}$

\section{Introduction}

Gliomas are ranked as the most aggressive brain tumors; they show a high frequency of invasion mediators such as angiogenic factors and chemokines (small-sized proteins, produced and released locally, intended for localized action) [1-3].

Simultaneous evaluation of multiple proteins in serum and cerebrospinal fluid allows for the identification of novel circulating biomarker panels helpful in disease diagnosis and treatment [4]. Therefore, in the last few years, proteomic approaches have been used to indicate potential cytokines, chemokines, and angiogenic factors for diagnosis and/or progression of primary brain tumors $[1,5,6]$. Using throughput xMAP technology, Albulescu et al. identified serum profiles of cytokines and angiogenic factors (IL-6, IL-1 $\beta$, IL-2, IL-10, TNF- $\alpha$, VEGF, FGF-2, and GM-CSF) altered in glioblastoma patients [1]. The authors highlighted that the evaluation of biomarker panels is more appropriate than single molecule analysis [1]. Studies by Popescu et al. also indicated the role of simultaneous identification of proteomic signature in the diagnosis and treatment of brain tumors, as they, by means of SELDI-ToF MS technology, indicated serum S100A8, S100A9, and CXCL4 proteins as a potential candidate for glioblastoma biomarkers [5]. A bio-plex system multimarker screening by Nijaguna et al., of circulating serum biomarkers in glioma patients, indicated 18 cytokines (interleukins: $-2,-3,-4,-6,-7,-10,-12,-17,-15$, MIP1 $\alpha$, LIF, TNF- $\alpha$, FGF basic, GM-CSF, IFN- $\gamma$, IL1R $\alpha, \operatorname{SCGF} \beta$, and $\beta$ NGF) discriminating glioma patients from healthy individuals [6]. The authors also proposed that the above-mentioned cytokines may be useful in monitoring response to the treatment and glioma recurrence [6].

Monocyte chemotactic protein-1 (MCP-1/CCL2) has been found in different tumor samples and may be recognized as a potential regulator of cancer progression [7, 8]. In vivo studies showed that a significant source of CCL2 is tumor epithelium [8]. Additionally, tumor cells themselves may be a major source of this protein. Expression and localization of mRNA and protein for CCL2 in human malignant glioma was found by Takeshima et al. [7]. Studies of other authors revealed that antibody-mediated blockade of CCL2 had an influence on the survival prolongation of glioma cells in mice and in humans [9]. These findings suggest that CCL2 may be a potential therapeutic target.

Interleukin-8 (IL-8), also known as CXCL8, is a member of the CXC family of chemokines [10]. Similar to the CCL2, IL-8 may be produced by the tumor cells itself and/or released by immune cells activated in response to tumor cell growth [11]. During inflammation, IL-8 takes part in carcinogenesis by acting directly on epithelial cells via NFKB1 pathway signaling. Additionally, IL-8 expression by tumor cells stimulates cancer cell proliferation, migration, as well as invasion [11, 12].

Intercellular adhesion molecule 1 (ICAM-1/CD54) is a nearly ubiquitous transmembrane glycoprotein. Elevated levels of this protein were related with certain malignancies [13]. Soluble ICAM-1 (sICAM-1) has been recognized as an indicator of vascular endothelial cell activation or damage [14]. It also assumes an inhibiting role for transmembrane ICAM-1-mediated activities such as the sensitivity of tumor cells to NK cell-mediated lysis [15].

In the last few years, great effort has been put into searching for diagnostic, prognostic, predictive, and therapeutic response biomarkers in glioma patients [16]; however, so far, no single circulating biomarker has been used in routine practice for management of these patients [17]. The search for these kinds of biomarkers still represents an exciting research area; therefore, the aim of the current study was the evaluation of serum and CSF concentrations of CCL2, IL-8, and ICAM-1 in patients with neuroepithelial tissue tumors as compared to non-tumoral patients, with no history of cancer as a comparative group. To exclude possible fluctuations of the blood-brain barrier and the blood-CSF barrier, we also calculated the indexes for each protein tested by referring the obtained results in CSF to values in serum. It would be of great interest to 
establish biomarkers measurable in biological fluids distinguishing patients with CNS tumors from non-tumoral subjects. Moreover, our studies may highlight potential factors which may indicate a direction for targeted therapy.

\section{Materials and methods}

\section{Subjects}

Samples (serum and cerebrospinal fluid) were collected between July 2015 and November 2016 from the Department of Neurosurgery, Clinical Hospital of the Medical University of Bialystok. The study group consisted of 20 patients (11 males/ 9 females, mean age 56 years, range 39-73 years) with previously untreated cerebral tumors of neuroepithelial tissue. The inclusion criterion was the histopathological examination result indicating astrocytic tumor (Table 1). The exclusion criterion was a brain tumor remission in medical history. The comparative group was composed of 20 non-tumoral subjects (4 males/16 females, mean age 56 years, range $30-70$ years) with unruptured intracranial aneurysms (UIAs), which is usually asymptomatic and only discovered incidentally [18]. The inclusion criterion was an absence of intracranial hemorrhage in medical history. The exclusion criterion was the occurrence of cancer in medical history or acute and chronic inflammatory conditions. The study was conducted in agreement with the Helsinki-II-declaration and was approved by the Bioethics Human Research Committee of the Medical University of Bialystok. All subjects included in the study gave their informed written consent.

\section{Sample collection and storage}

Procedures on patients were performed under a general anesthetic during neurosurgery at the Department of Neurosurgery of the Clinical Medical Hospital in Bialystok. Craniotomy has been performed on all subjects included in the study. In patients undergoing tumor resection, its size and localization was tailored according to the location and size of the tumor, the preferred access route, and surrounding anatomy. Clipping of an aneurysm required an opening in the fronto-temporal region (aka pterional craniotomy). Regardless of operation type or location, after placing the patient's head in a three-pin Mayfield headholder, the surgical field was prepared in a standard fashion. Skin incision preceded the lifting of bone flap and lancing of dura mater, which allowed the visualization of the arachnoid membrane and subarachnoid space. With the aid of an operating microscope, the subarachnoid space was carefully opened and CSF aspirated with a single-use, sterile syringe, and soft venous catheter. The aforementioned steps were taken at the very beginning of each procedure, before any bleeding could occur. This routine allowed us to keep the
CSF clean of blood and not mix with warm saline solution used for irrigation.

All patients' blood samples were drawn without stasis. Tubes containing blood collected without anticoagulant and CSF samples were centrifuged for $20 \mathrm{~min}$ at $1000 \times \mathrm{g}$. The obtained serum and CSF supernatant were stored at $-80{ }^{\circ} \mathrm{C}$ until further analysis.

\section{CSF and serum CCL2, IL-8, and ICAM-1 concentrations evaluation}

Concentrations of CCL2 were measured using an ELISA Quantikine ${ }^{\circledR}$ Human CCL2/CCL2 Immunoassay kit (Catalog number: DCP00; R\&D Systems Europe Ltd., Abingdon, England) according to the manufacturer's instructions. Samples were diluted twofold prior to analysis. The manufacturer of the assay kit referred to the intra-assay coefficient of variation (CV\%) as $7.8 \%$ at CCL2 mean concentration of $76.7 \mathrm{pg} / \mathrm{mL}, \mathrm{SD}=6.0 \mathrm{pg} / \mathrm{mL}$.

Concentrations of IL-8 were measured using an ELISA Quantikine ${ }^{\circledR}$ Human CXCL-8/IL-8 Immunoassay kit (Catalog number: D8000C; R\&D Systems Europe Ltd., Abingdon, England) according to the manufacturer's instructions. Samples were not diluted prior to analysis. The manufacturer of the assay kit referred to the intra-assay coefficient of variation $(\mathrm{CV} \%)$ as $5.6 \%$ at IL-8 mean concentration of $168 \mathrm{pg} / \mathrm{mL}, \mathrm{SD}=9.4 \mathrm{pg} / \mathrm{mL}$.

Concentrations of sICAM-1 were measured using an ELISA Quantikine ${ }^{\circledR}$ Human ICAM-1/CD54 Allele-specific Immunoassay kit (Catalog number: DCD540; R\&D Systems Europe Ltd., Abingdon, England). According to the ELISA protocol, CSF and serum were diluted 20-fold prior to analysis. The manufacturer of the assay kit referred to the intraassay coefficient of variation (CV\%) as $3.7 \%$ at ICAM-1 mean concentration of $4.61 \mathrm{ng} / \mathrm{mL}, \mathrm{SD}=0.17 \mathrm{ng} / \mathrm{mL}$.

The obtained results were statistically analyzed with the use of the STATISTICA 12.0 PL software (StatSoft Inc., Tulsa, USA). The concentrations of parameters tested did not follow a normal distribution in the preliminary statistical analysis ( $X^{2}$ test), thus nonparametric statistical analysis was employed. The Mann-Whitney test was used in order to compare two independent samples. Correlation coefficients were obtained by applying Spearman's rank method. If not stated otherwise, the values for each given measured variable are presented as medians and interquartile ranges. Differences were considered statistically significant for $P<0.05$. Receiver operator characteristic (ROC) curves were generated to calculate the areas under the ROC curves (AUCs). The Youden index, a function of sensitivity and specificity, was estimated to indicate an optimal threshold value (cut-off point) for the parameters tested. The Youden index is a commonly used measure to evaluate the effectiveness of new biomarkers 


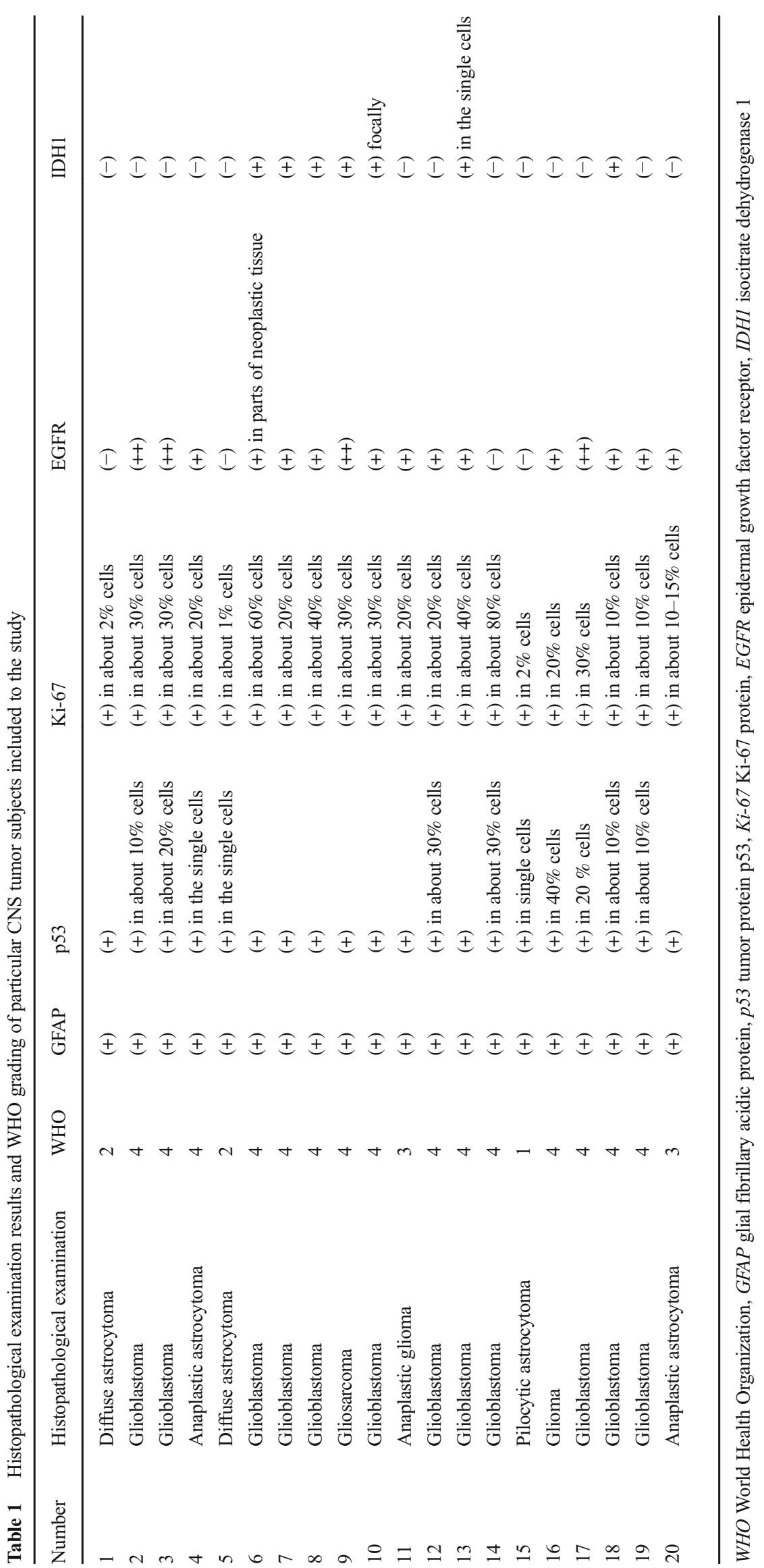


and gives equal weight to sensitivity and specificity for the values of the biomarker tested [19].

\section{Results}

Regardless of the parameter tested and the patient group (CNS brain tumors or non-tumoral individuals), statistically relevant differences were found between concentrations obtained in CSF compared to values obtained in serum for all proteins tested $(P<0.05)$. Significant differences were found between the study groups in CSF for IL-8, while in serum, differences were obtained for CCL2 and sICAM-1 (Table 2). Correlation coefficient analysis did not reveal a relation between concentrations of proteins tested in the serum with values in the CSF, except for moderate correlations for IL-8 in CNS brain tumors ( $R=0.50, P=0.024)$ and for CCL2 in the non-tumoral group $(R=0.45, P=0.044)$.

\section{Serum and CSF results}

Serum IL-8 concentrations revealed a tendency to be higher in patients with brain tumors as compared to non-tumoral individuals, but the differences obtained were not significant. CSF IL-8 concentrations were statistically elevated in CNS tumor patients as compared to controls $(P=0.000)$. Serum CCL2 and sICAM-1 concentrations were significantly decreased in CNS tumors as compared to non-tumoral subjects $(P=0.002$ and $P=0.026$, respectively). CSF CCL2 and SICAM-1 concentrations revealed a tendency to be lower in CNS tumors as compared to the control group, but the differences obtained were not significant. It should be highlighted that sICAM-1 concentrations in the brain tumor group were detectable only in 6 out of $20 \mathrm{CSF}$ samples. In the group of non-tumoral subjects, sICAM-1 concentrations were detected in only 3 out of 20 CSF samples (Table 2).

\section{Indexes results}

To exclude possible impairment of the blood-CSF barrier and/ or blood brain barrier (BBB) functions as potential sources influencing concentrations of proteins tested, the CSF concentrations were related to the concentrations obtained in the serum by calculating the indexes, as was described elsewhere [20]. IL- $8_{\text {Index }}$ was significantly higher in CNS brain tumor individuals as compared to the control group $(P=0.002)$. We did not find the utility for the calculation for either the CCL $2_{\text {Index }}$ or the sICAM-1 $1_{\text {Index }}$ (Table 2).

\section{Diagnostic criteria for proteins tested}

Among proteins tested in the serum, a higher area under the ROC curve (AUC) revealed CCL2 compared to ICAM-1 in differentiating subjects with CNS brain tumors from nontumoral subjects. Both AUCs were statistically higher than $\mathrm{AUC}=0.5$, which indicates their diagnostic usefulness (Fig. 1, Table 3). AUC for CSF IL-8 was higher than for its index; however, both AUCs were statistically higher than $\mathrm{AUC}=0.5$, which indicates their diagnostic usefulness for differentiating patients with primary brain tumors from nontumoral individuals (Fig. 2, Table 3).
Table 2 Serum, CSF, and indexes values obtained in patients with CNS brain tumors as compared to non-tumoral individuals. Values are present as median and interquartile range

\begin{tabular}{|c|c|c|c|}
\hline & CNS brain tumors & Non-tumoral group & $P$ value \\
\hline \multicolumn{4}{|c|}{ Serum } \\
\hline CXCL8/IL-8 & $13.01(6.85-16.45)$ & $9.98(9.02-12.71)$ & NS \\
\hline CCL2/MCP-1 & $151.84(123.89-213.70)$ & $247.40(217.10-351.40)$ & 0.002 \\
\hline ICAM-1/CD54 & $137.48(118.70-190.04)$ & $182.69(142.39-232.10)$ & 0.026 \\
\hline \multicolumn{4}{|c|}{$\mathrm{CSF}$} \\
\hline CXCL8/IL-8 & $65.13(45.36-103.00)$ & $30.48(23.81-36.82)$ & 0.000 \\
\hline CCL2/MCP-1 & $409.70(207.34-735.30)$ & $458.70(366.00-726.00)$ & NS \\
\hline ICAM-1/CD54 & $16.68(6.78-25.84)$ & $19.22(13.90-23.76)$ & NS* \\
\hline \multicolumn{4}{|c|}{ Indexes } \\
\hline CXCL8/IL-8 & $7.72(3.91-9.81)$ & $2.90(2.13-4.19)$ & 0.002 \\
\hline CCL2/MCP-1 & $2.74(1.39-4.74)$ & $1.71(1.42-2.03)$ & NS \\
\hline ICAM-1/CD54 & $0.12(0.04-0.24)^{\mathrm{a}}$ & $0.11(0.06-0.15)^{\mathrm{b}}$ & NS* \\
\hline
\end{tabular}




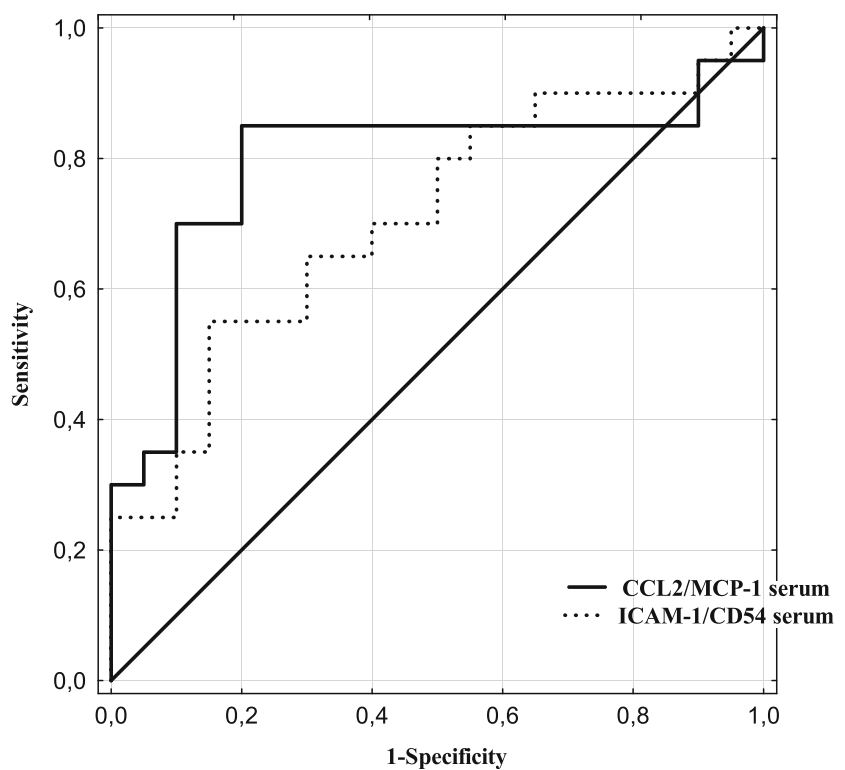

Fig. 1 Areas under the ROC curves for serum CCL2 (AUC $=0.793$; cutoff: $216.20 \mathrm{pg} / \mathrm{mL}$ ) and sICAM-1 (AUC=0.708; cut-off: $138.68 \mathrm{ng} / \mathrm{mL}$ ) in differentiation between CNS tumor patients and non tumoral individuals

\section{Discussion}

According to the literature, free chemokine concentrations in normal human serum are mostly below the lower limit of detection. An explanation for this may be the presence of immune complexes in which the epitope is embedded [21].

However, our study revealed detectable concentrations, above the lower limit of detection, for IL-8 and CCL2 in all patients' samples, regardless of the material (serum/CSF) or study group (CNS brain tumors/non-tumoral subjects) analyzed.

Also, serum sICAM-1 concentrations were detected in all the tested samples, which was previously confirmed by the studies of Nano et al., as they revealed that SICAM- 1 serum levels were not significantly increased in GBL and astrocytoma patients compared with another type of tumor (lung and kidney cancer) [13]. Surprisingly, CSF levels for the adhesion molecule sICAM-1 were below the lower limit of the test sensitivity in most of the samples analyzed (we found sICAM-1 concentrations in only 6 of the 20 CSF samples of
CNS brain tumor patients and in only 3 of the $20 \mathrm{CSF}$ of the control samples).

Rieckmann et al. found a low-level expression of mRNA for sICAM in human cerebral endothelial cells (obtained from early post-mortem human brains), U251 glioma cells, blood mononuclear cells, and cerebrospinal fluid cells of patients with aseptic meningitis [22]. Additionally, they found that upon stimulation with LPS or TNF- $\alpha$, cerebral endothelial cells and U251 glioma cells were capable of releasing sICAM-1 into the culture supernatant [22].

So far, detectable sICAM-1 concentrations in CSF have been found by Brandsma et al. [23] and Tiberti et al. [24]; however, the study populations were leptomeningeal metastases subjects and human African trypanosomiasis individuals, respectively. Moreover, Brandsma et al. tested sICAM-1 levels by means of multiplex immuno-assay (MIA) and paired antibodies from different commercial vendors [23], thus we could not estimate the concentrations of the targeted protein and we performed the experiment with the dilution factor recommended by the manufacturer. Based on the obtained results, we hypothesize, that for sICAM-1 analysis in the CSF, we did not use the appropriate dilution factor and the best way to test the sICAM-1 concentrations in the CSF is to analyze undiluted samples. However, we could not re-test undiluted CSF samples because of a lack of material in order to confirm this. Despite the inappropriate dilution factor, the second reason for the failed SICAM-1 concentrations results in the CSF might be the sensitivity of the assay kit (there is a possibility that more sensitive assays are needed).

Current studies have revealed, that regardless of the parameter tested and the patient group, statistical differences were to be found between concentrations obtained in CSF compared to values obtained in serum for all proteins measured. Significant differences were found between the study groups in CSF for IL-8, while in serum, differences were obtained for CCL2 and sICAM-1. Our findings indicate altogether, that for individual biomarkers (IL-8 and CCL2, sICAM-1), the appropriate material, respectively CSF or serum, should be chosen and quantitatively tested.

Our study revealed statistically increased CSF IL-8 concentrations in CNS brain tumor patients as compared to non-

Table 3 Diagnostic usefulness of serum CCL2, sICAM-1, and CSF IL-8 as well as IL-8 $8_{\text {Index }}$

\begin{tabular}{lllllllllll}
\hline & Cut-off & Youden index & AUC & SE & $P$ & Sensitivity [\%] & Specificity [\%] & PPV [\%] & NPV [\%] & ACC [\%] \\
\hline Serum CCL2 & 216.20 & 0.65 & 0.793 & 0.080 & 0.000 & 85 & 80 & 81 & 84 & 83 \\
Serum sICAM-1 & 138.68 & 0.40 & 0.708 & 0.083 & 0.012 & 55 & 85 & 79 & 65 & 70 \\
CSF IL-8 & 39.48 & 0.60 & 0.860 & 0.062 & 0.000 & 80 & 80 & 80 & 80 & 80 \\
IL-8 Index & 7.48 & 0.55 & 0.793 & 0.074 & 0.000 & 55 & 100 & 100 & 69 & 78 \\
\hline
\end{tabular}

Cut-off optimal cut-off based on the highest Youden index, $A U C$ area under the ROC curve, $S E$ standard error, $P P V$ positive predictive value, $N P V$ negative predictive value, $A C C$ diagnostic accuracy 


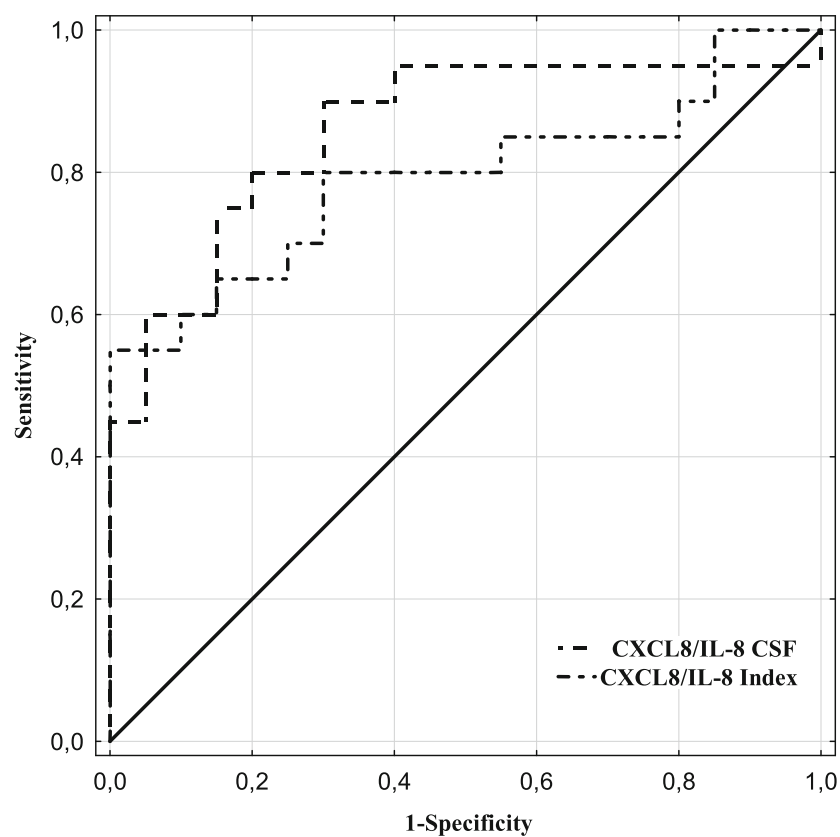

Fig. 2 Areas under the ROC curves for CSF IL-8 (AUC=0.860; cutoff: $39.486 \mathrm{pg} / \mathrm{mL}$ ) and it's index (AUC=0.793; cut-off: 7.48) in differentiation between CNS tumor patients and non tumoral individuals

tumoral subjects, which indicates that this chemokine may be synthesized within the CNS tissue during astrocytic tumor development and IL-8-related neuroinflammation can have a significant influence on glioblastoma (GBM) progression. Studies indicated that IL- 8 is secreted by activated monocytes and macrophages expressed in microglia and it is a proangiogenic factor in gliomas [25-28]. Moreover, enhanced secretion of IL- 8 by glioma cells was also reported by Yeung et al. [29]. IL-8 was also inversely correlated with GBM patients' survival [30]. GBM cells, which secrete IL-8, promote angiogenesis and microvascular endothelial permeability [9]. IL-8 can also regulate GBM associated "cancer stem cells" (CSCs) and was associated with tumor grade in astrocytic neoplasms [31]. IL-8 induces the growth and migration of CSCs via receptors CXCR1 and CXCR2. Observations concerning human microvascular ECs revealed that the blockade of either receptor decreases IL-8-related chemotaxis. de la Iglesia et al. showed that in PTEN-deficient glioblastoma cells, repression of IL-8 can inhibit glioma cell proliferation and invasiveness [32].

Originally, CCL2 has been purified to homogeneity and cDNA, then cloned from the glioma cell line $[3,8]$. The production of CCL2 by different types of human malignant glioma cell lines has been well documented. It was also noted that malignant glioma cells produce more CCL2 compared to other tumor cell lines, such as melanoma or malignant fibrous histiocytoma [33].

According to best knowledge, our study is the second which evaluated CCL2 concentrations in the CSF of patients with CNS brain tumors. However, results of our group are in disagreement with the reports of Kuratsu et al., which revealed that CCL2 concentrations in CSF samples from malignant glioma subjects were statistically higher in comparison to individuals with benign glioma, as well as compared to nontumoral patients [33]. We did not reveal significant differences for CSF CCL2 between the brain tumor group compared to patients with no tumor. Moreover, CCL2 concentrations revealed a tendency to be lower in brain tumors as compared to non-tumoral individuals. In our opinion, the discrepancies between the results of these two studies may result from the following: (1) different antibodies applied by means of ELISA (Kuratsu et al. used rabbit polyclonal antibody and mouse monoclonal antibody (clone E11) against human CCL2); our group applied a ready-to-use ELISA plate coated with a monoclonal antibody specific for human and recombinant CCL2 from a well-known vendor (R\&D Systems) and/or (2) not homogenous CSF samples (Kuratsu et al. collected CSF to analyze from different CNS spaces (lumbar interspace/cisternography by drainage during the surgery/ directly from cisterns or brain ventricles), while our group collected all CSF samples from the supratentorial subarachnoid space and/or (3) a different number of non-tumoral subjects (Kuratsu et al. $N=7$, our group $N=20$ ). We have one more explanation as to why in our study, CSF CCL2 concentrations were lower as compared to non-tumoral subjects: this may be due to the fact that CNS astrocytic tumors, which grow inside the tumor mass, may not have the possibility to make contact with the CSF and thus CCL2 cannot be released into the cerebrospinal fluid.

In our study, serum CCL2 and sICAM-1 concentrations were significantly decreased in CNS tumors as compared to the non-tumoral group. From both of the proteins tested in the serum, a higher clinical significance was revealed for CCL2. However, the CNS is actually still not recognized as an immune privileged site, as there is no strong evidence in the available literature that the protective brain barriers are meaningfully altered in malignant gliomas. Therefore, blood CNS tumor biomarkers, defined as measurable indicators of diseases, their progress and response to therapeutic intervention, are of great clinical value. Biomarkers, which may be detected and measured in the peripheral blood, are of important interest due to the fact that blood is easy to obtain and the blood collection procedure is not as traumatic as lumbar puncture and involves only momentary discomfort to the patient.

\section{Advantages and disadvantages of the study}

The first advantage of our study was the evaluation of IL-8, CCL-2, and ICAM-1 concentrations both in the CSF as well as in the peripheral blood and calculating indexes for each protein tested. Such an approach limits the influence of protein fluctuation present in the blood, on the concentrations of corresponding proteins in the $\mathrm{CSF}$ and interpretative difficulties 
resulting from this. A second strong point of our research was the evaluation of proteins tested in CSF collected from the same CNS interspace, so these samples were relatively homogenous.

Our study also has a few disadvantages: (1) the small study group, which we try to compensate for by equaling out the number of participants, included to tumoral patients $(N=20)$ and non-tumoral subjects $(N=20)$; (2) values obtained in patients with astrocytic tumors should be compared with other primary CNS tumors (e.g., meningeal tumors) as well as metastatic tumors (a similar study is in progress); (3) analysis of the clinical utility of proteins tested is limited, due to the efficiency of tests changing with the prevalence of the disease and the position of the threshold value (if the sensitivity related to a selected cut-off value is higher than the specificity, the efficiency will increase with an increasing prevalence of the disease; if the specificity related to a selected threshold value is higher than the sensitivity, the efficiency will decrease with an increasing prevalence of the disease). In our study, the number of brain tumor subjects was equal to the number of subjects from the comparative group, so the test analysis did not reflect the prevalence of astrocytic brain tumors in the population; (4) the astrocytic tumor group is relatively small and not histologically homogeneous; thus, it is difficult to discuss biomarkers specificity.

\section{Conclusion}

In conclusion, our results support the assumption that CSF IL8 concentrations could play a crucial role in predicting the presence of astrocytic tumors. However, there is a need for further studies, if IL-8 may also be recognized as a helpful biomarker assessing patients' response to the applied therapy. From the biomarkers tested in the blood, CCL2 seems to have clinical utility; therefore, for individual biomarkers (IL-8 and CCL2, sICAM-1), the appropriate material, respectively CSF or serum, should be chosen and quantitatively tested. To sum up, increased CSF IL-8 with decreased serum CCL2 gives a biomarker pattern, which in combination with a conventional therapeutic strategy may be helpful in the management of CNS astrocytic brain tumors.

Acknowledgments We are grateful to Jan Dobrodumow for his language assistance.

Compliance with ethical standards The study was conducted in agreement with the Helsinki-II-declaration and was approved by the Bioethics Human Research Committee of the Medical University of Bialystok. All subjects included in the study gave their informed written consent.

Conflict of interest The authors declare that they have no conflict of interests.
Open Access This article is distributed under the terms of the Creative Commons Attribution 4.0 International License (http:// creativecommons.org/licenses/by/4.0/), which permits unrestricted use, distribution, and reproduction in any medium, provided you give appropriate credit to the original author(s) and the source, provide a link to the Creative Commons license, and indicate if changes were made.

\section{References}

1. Albulescu R, Codrici E, Popescu ID, Mihai S, Necula LG, Petrescu D, Teodoru M, Tanase CP (2013) Cytokine patterns in brain tumour progression. Mediators Inflamm 2013:979748, 7 p

2. Jakubowicz-Gil J, Langner E, Bądziul D, Wertel I, Rzeski W (2013) Apoptosis induction in human glioblastoma multiforme T98G cells upon temozolomide and quercetin treatment. Tumour Biol 34(4): 2367-2378

3. Corsi MM, Leone G, Fulgenzi A, Wasserman K, Leone F, Ferrero ME (1999) RANTES and MCP-1 chemokine plasma levels in chronic renal transplant dysfunction and chronic renal failure. Clin Biochem 32(6):455-460

4. Koper OM, Kamińska J, Kemona H, Dymicka-Piekarska V (2015) Application of the bead based technique in neurodegeneration: a literature review. Neurodegener Dis 15(5):281-293

5. Popescu ID, Codrici E, Albulescu L, Mihai S, Enciu AM, Albulescu R, Tanase CP (2014) Potential serum biomarkers for glioblastoma diagnostic assessed by proteomic approaches. Proteome Sci 12(1):47

6. Nijaguna MB, Patil V, Hegde AS, Chandramouli BA, Arivazhagan A, Santosh V, Somasundaram K (2015) An eighteen serum cytokine signature for discriminating glioma from normal healthy individuals. PLoS One 10(9):e0137524

7. Takeshima H, Kuratsu J, Takeya M, Yoshimura T, Ushio Y (1994) Expression and localization of messenger RNA and protein for monocyte chemoattractant protein-1 in human malignant glioma. J Neurosurg 80(6):1056-1062

8. Negus RP, Stamp GW, Relf MG, Burke F, Malik ST, Bernasconi S, Allavena P, Sozzani S, Mantovani A, Balkwill FR (1995) The detection and localization of monocyte chemoattractant protein-1 (MCP-1) in human ovarian cancer. J Clin Invest 95(5):2391-2396

9. Seike T, Fujita K, Yamakawa Y, Kido MA, Takiguchi S, Teramoto N, Iguchi H, Noda M (2011) Interaction between lung cancer cells and astrocytes via specific inflammatory cytokines in the microenvironment of brain metastasis. Clin Exp Metastasis 28:13-25

10. Moore BB, Arenberg DA, Stoy K, Morgan T, Addison CL, Morris SB, Glass M, Wilke C, Xue YY, Sitterding S, Kunkel SL, Burdick MD, Strieter RM (1999) Distinct CXC chemokines mediate tumorigenicity of prostate cancer cells. Am J Pathol 154(5):1503-1512

11. Dobrzycka B, Mackowiak-Matejczyk B, Terlikowska KM, Kulesza-Bronczyk B, Kinalski M, Terlikowski SJ (2013) Serum levels of IL-6, IL-8 and CRP as prognostic factors in epithelial ovarian cancer. Eur Cytokine Netw 24(3):106-113

12. Domanska UM, Kruizinga RC, den Dunnen WF, Timmer-Bosscha H, de Vries EG, Walenkamp AM (2011) The chemokine network, a newly discovered target in high grade gliomas. Crit Rev Oncol Hematol 79(2):154-163

13. Nano R, Capelli E, Argentina F, Facoetti A, Gerzeli G (2003) Evaluation of serum levels of cytokines and intercellular adhesion molecule-1 (ICAM-1) in astrocytic tumours. Cell Mol Biol (Noisyle-grand) 49(4):525-528 
14. Dymicka-Piekarska V, Guzinska-Ustymowicz K, Kuklinski A, Kemona H (2012) Prognostic significance of adhesion molecules (sICAM-1, sVCAM-1) and VEGF in colorectal cancer patients. Thromb Res 129(4):e47-e50

15. Tsakadze NL, Zhao Z, D'Souza SE (2012) Interactions of intercellular adhesion molecule-1 with fibrinogen. Trends Cardiovasc Med 12(3):101-118

16. Kalinina J, Peng J, Ritchie JC, Van Meir EG (2011) Proteomics of gliomas: initial biomarker discovery and evolution of technology. Neuro-Oncology 13(9):926-942

17. Santangelo A, Tamanini A, Cabrini G, Dechecchi MC (2017) Circulating microRNAs as emerging non-invasive biomarkers for gliomas. Ann Transl Med 5(13):277

18. Ojini FI (2005) Natural history of cerebral saccular aneurysms. West Afr J Med 24(1):70-74

19. Kamińska J, Koper OM, Dymicka-Piekarska V, Motybel-Iwańczuk E, Ołdziej A, Kemona H (2016) Serum soluble CD40L concentration depending on the stage of multiple myeloma and its correlation with selected angiogenic cytokines. Pol Arch Med Wewn 126(5): 321-329

20. Koper OM, Kamińska J, Grygorczuk S, Zajkowska J, Kemona H (2016) CXCL9 concentrations in cerebrospinal fluid and serum of patients with tick-borne encephalitis. Arch Med Sci. https://doi.org/ 10.5114/aoms.2016.58667

21. Leonard EJ (1996) Plasma chemokine and chemokineautoantibody complexes in health and disease. Methods 10(1): $150-157$

22. Rieckmann P, Michel U, Albrecht M, Brück W, Wöckel L, Felgenhauer K (1995) Cerebral endothelial cells are a major source for soluble intercellular adhesion molecule-1 in the human central nervous system. Neurosci Lett 15 186(1):61-64

23. Brandsma D, Voest EE, de Jager W, Bonfrer H, Algra A, Boogerd W, Korse T, Reijneveld JC, Verbeek MM, Rijkers G, Taphoorn MJ (2006) CSF protein profiling using Multiplex Immuno-assay: a potential new diagnostic tool for leptomeningeal metastases. J Neurol 253(9):1177-1184

24. Tiberti N, Lejon V, Hainard A, Courtioux B, Robin X, Turck N, Kristensson K, Matovu E, Enyaru JC, Mumba Ngoyi D, Krishna S, Bisser S, Ndung'u JM, Büscher P, Sanchez JC (2013) Neopterin is a cerebrospinal fluid marker for treatment outcome evaluation in patients affected by Trypanosoma brucei gambiense sleeping sickness. PLoS Negl Trop Dis 7(2):e2088

25. Brat DJ, Bellail AC, Van Meir EG (2005) The role of interleukin-8 and its receptors in gliomagenesis and tumoral angiogenesis. Neuro-Oncology 7:122-133

26. Harada A, Sekido N, Akahoshi T, Wada T, Mukaida N, Matsushima K (1994) Essential involvement of interleukin-8 (IL-8) in acute inflammation. J Leukoc Biol 56:559-564

27. Lee YB, Nagai A, Kim SU (2002) Cytokines, chemokines, and cytokine receptors in human microglia. J Neurosci Res 69:94-103

28. Ilhan-Mutlu A, Wagner L, Widhalm G, Wöhrer A, Bartsch S, Czech T, Heinzl H, Leutmezer F, Prayer D, Marosi C, Base W, Preusser M (2012) Exploratory investigation of eight circulating plasma markers in brain tumor patients. Neurosurg Rev 36(1):4555 discussion 55-56

29. Yeung YT, Bryce NS, Adams S, Braidy N, Konayagi M, McDonald KL, Teo C, Guillemin GJ, Grewal T, Munoz L (2012) p38 MAPK inhibitors attenuate pro-inflammatory cytokine production and the invasiveness of human U251 glioblastoma cells. J Neuro-Oncol 109(1):35-44

30. Lathia JD, Li M, Hall PE, Gallagher J, Hale JS, Wu Q, Venere M, Levy E, Rani MR, Huang P, Bae E, Selfridge J, Cheng L, Guvenc H, McLendon RE, Nakano I, Sloan AE, Phillips HS, Lai A, Gladson CL, Bredel M, Bao S, Hjelmeland AB, Rich JN (2012) Laminin alpha 2 enables glioblastoma stem cell growth. Ann Neurol 72(5):766-778

31. Infanger DW, Cho Y, Lopez BS, Mohanan S, Liu SC, Gursel D, Boockvar JA, Fischbach C (2013) Glioblastoma stem cells are regulated by interleukin- 8 signaling in a tumoral perivascular niche. Cancer Res 73(23):7079-7089

32. de la Iglesia N, Konopka G, Lim KL, Nutt CL, Bromberg JF, Frank DA, Mischel PS, Louis DN, Bonni A (2008) Deregulation of a STAT3-interleukin 8 signaling pathway promotes human glioblastoma cell proliferation and invasiveness. $\mathrm{J}$ Neurosci 28(23):5870-5878

33. Kuratsu J, Yoshizato K, Yoshimura T, Leonard EJ, Takeshima H, Ushio Y (1993) Quantitative study of monocyte chemoattractant protein-1 (MCP-1) in cerebrospinal fluid and cyst fluid from patients with malignant glioma. J Natl Cancer Inst 85(22):1836-1839 